\title{
Planning Considerations for Deep Level Mining at Perseverance Mine
}

\author{
D. Gaudreau BHP Billiton Nickel West, Perseverance Mine, Australia
}

I. Thin BHP Billiton Nickel West, Perseverance Deeps Project, Australia

A. Haile BHP Billiton Nickel West, Business Development, Australia

\begin{abstract}
Given the high stress and poor rock mass conditions found at the Perseverance Mine, appropriate mine engineering and planning techniques are necessary, amongst other mine operational aspects, to perform sustainable mining at current and projected depths. This paper describes the processes and techniques relevant to mine planning and the geotechnical engineering considerations used at Perseverance in the context of deep mining in the Agnew-Wiluna Greenstone Belt. Perseverance Mine produces nickel sulphide ore using sub-level caving and long-hole stoping, and is wholly owned by BHP-Billiton Nickel West. The planning efforts relating to the current sub-level caving operation and the proposed future transition to block caving at a depth in excess of one kilometre are discussed.
\end{abstract}

\section{Introduction}

The Perseverance mine is part of Leinster Nickel Operations (LNO), located in the Northern Goldfields of Western Australia. The mine is $400 \mathrm{~km}$ north of Kalgoorlie and $900 \mathrm{~km}$ north-east of Perth. Charter and commercial airline services operate from the airstrip located $2 \mathrm{~km}$ south-west of the operation.

Seltrust discovered the Perseverance deposit in 1971 and formed a joint venture with MIM Holdings in 1974 to develop a mine at this site. The Agnew Mining Company (AMC) joint venture commenced operations in 1978. Mining by AMC in the Perseverance orebody was limited to an area above the 3 Level, $500 \mathrm{~m}$ below surface. The majority of mining was conducted in the narrow 1A orebody that consisted of massive sulphide ore of higher grade and better metallurgical characteristics than the main ultramafic disseminated orebody. Several different mining methods were utilised in the main orebody including post pillar cut and fill, open stoping, stoping under rock fill and vertical crater retreat (Carthew and Auld, 2006).

A combination of difficult ground conditions but predominately low nickel metal prices terminated the mining activity in 1986. Collapse of the worked areas above the $10145 \mathrm{mRL}$ level, $380 \mathrm{~m}$ below surface, has occurred, preventing access to the remnant ore in the old workings of the main orebody.

The operation and leases were purchased in December 1988 by WMC, and renamed Leinster Nickel Operations (LNO). In January 1989 WMC commenced rehabilitation of the concentrator and open pit mining at the Perseverance mine. Mining of the Rocky's Reward open pit deposit, two kilometres to the north of Perseverance, also commenced the same year. The Perseverance underground was concurrently developed to eventually replace the open-cut operations, and sub-level caving of the main disseminated ore body recommenced on the southern end of 10145 Level from 1994 onwards.

BHP Billiton took ownership of LNO through its acquisition of WMC Resources in 2005. It is now part of Nickel West, which operates the Western Australian nickel assets of the Stainless Steel Materials customer service group.

The underground workings of the Perseverance mine are accessed by both a decline and a shaft. The compartmented main shaft is $7.5 \mathrm{~m}$ in diameter and is used for both haulage and the transport of personnel and materials. The shaft extends from the surface down to $1162 \mathrm{~m}$ at the base of the current ore reserve, located on 11 Level. The decline is nominally $5.5 \times 5.5 \mathrm{~m}$ and extends from a box-cut on the surface to the base of the shaft.

The main disseminated orebody continues to be mined using sub-level caving techniques. Production is currently active at depths of 825 to $1025 \mathrm{~m}$ in various mining zones. The Sub-Level Cave (SLC) area is the 
main disseminated Nickel resource. An extension of the SLC to the North, between 9815 and 9590 mRLs, is known as the Hangingwall Limb (HWL). The thickness of the HWL resource is 30 to $50 \mathrm{~m}$, versus 80 to $150 \mathrm{~m}$ for the SLC. Long-hole open stoping of the HWL was trialled in early 2003 at a depth of $910 \mathrm{~m}$. Ground conditions resulted in operational problems that impeded production performance. The HWL is now successfully being mined using sub-level caving techniques, albeit with a relatively narrow footprint compared to other sub-level caving operations. The mining horizon of the HWL is currently at the 9715 Level, $810 \mathrm{~m}$ below surface.

The P1 Progress shoot is also being mined using sub-level caving. Its footprint is nominally $120 \mathrm{~m}$ in length by $30 \mathrm{~m}$ in thickness, making it one of the narrowest sub-level caves in the world. Production is currently active on the 9515 level, $1010 \mathrm{~m}$ below surface.

The 1A ore body has been mined intermittently for the life of Perseverance underground. As mining progressed deeper, geotechnical issues have increased. The mining system has adapted, changing from sublevel open stoping, to sub-level open stoping with rib pillars, to sub-level open stoping with ribs and back fill. The remaining reserve is planned to be mined by sub-level open stoping with paste fill. In addition, the size of the central and regional pillars has been increased. Production is due to recommence from the 1A orebody on the 9540 level in late 2007, at $985 \mathrm{~m}$ below surface. Figure 1 is plan of the various mining zones on 6 Level, the shaded area indicating $>1 \%$ Nickel mineralisation. Only the very top of the Progress shoot extends to this horizon.

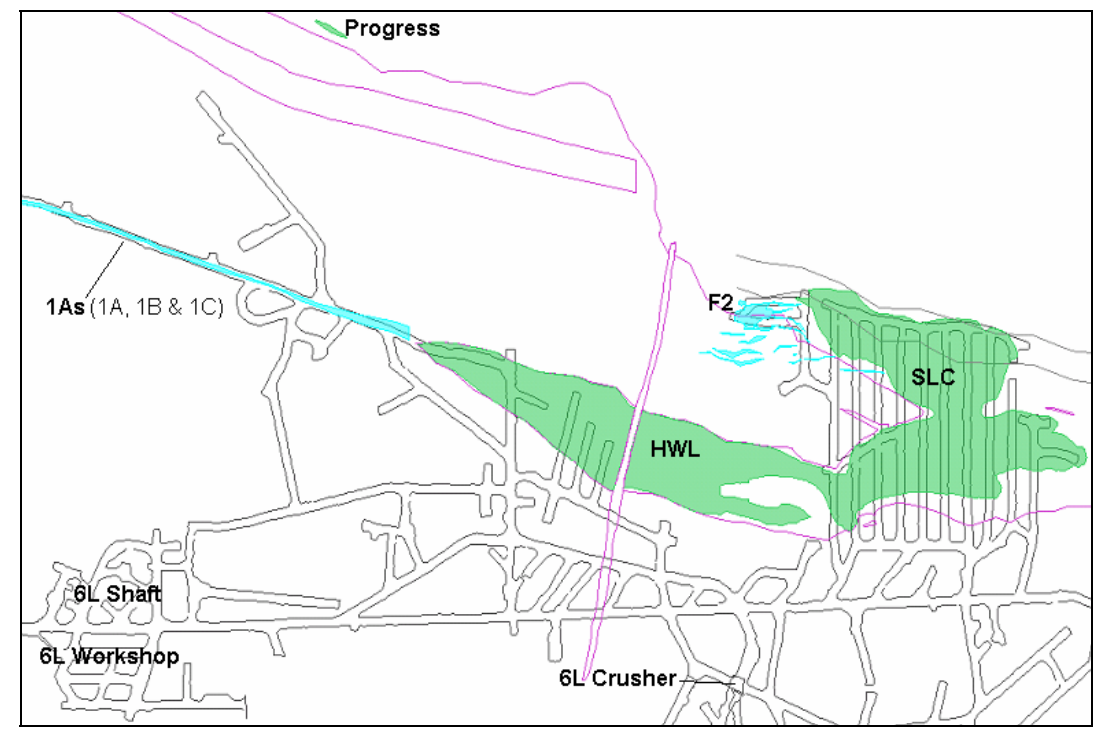

Figure 1 Plan view of mining zones at 6 Level $(9760 \mathrm{mRL})$

After a decade of mining at Perseverance, the operation is actively pursuing the deepening of its operation to 14 Level, roughly $1400 \mathrm{~m}$ below surface. The operation will change from sub-level cave mining techniques to block caving. This paper summarises important considerations for mine planning for the deep mining environment at Perseverance.

\section{Importance of setting a strategic direction}

Throughout the years, LNO has set a strategic direction for its operations. This enabled the conception of operating plans and budgets and the anticipation of critical milestones likely to affect the operation: catering for the global and the regional environment, and the investment of resources in appropriate opportunities.

The focus of strategic planning is on the long term aspects of the mine operation, while that of tactical planning is on the shorter term objectives. For the mine planning and geotechnical engineering initiatives, the scope of the business plan is summarised on a yearly basis. This facilitates alignment of the technical services efforts with those of the regional business. The plans are reviewed and resourced adequately to ensure that the mine operates to plan. Figure 2 summarises the mine planning initiatives for the calendar year 2007. 


\section{Strategic direction: plan, anticipate, project}

\begin{tabular}{|c|c|c|c|}
\hline Plan 1 & Plan 2 & Plan 3 & Plan 4 \\
\hline $\begin{array}{l}\text { Standardise and } \\
\text { implement business } \\
\text { division-wide mine } \\
\text { planning software }\end{array}$ & $\begin{array}{l}\text { Complete Life of } \\
\text { Resource Plans for } \\
\text { each mining zone }\end{array}$ & $\begin{array}{l}\text { Proceed to long term } \\
\text { fleet and financial } \\
\text { planning }\end{array}$ & $\begin{array}{l}\text { Focus on the materials } \\
\text { handling system, move } \\
\text { the right material out }\end{array}$ \\
\hline \multicolumn{4}{|c|}{ Deliver to plan, prevent gaps to the ore flow } \\
\hline Tactic 1 & Tactic 2 & Tactic 3 & Tactic 4 \\
\hline $\begin{array}{l}\text { Standardise short term } \\
\text { scheduling software to } \\
\text { consolidate delivery } \\
\text { plan to smelter }\end{array}$ & $\begin{array}{l}\text { Comply to Fatal Risk } \\
\text { Control Protocols } \\
\text { Proceed to Field } \\
\text { Leadership }\end{array}$ & $\begin{array}{l}\text { Ensure final mine } \\
\text { designs are completed } 6 \\
\text { months ahead }\end{array}$ & $\begin{array}{l}\text { Proceed to materials } \\
\text { handling improvement } \\
\text { strategy } \\
\text { implementation }\end{array}$ \\
\hline
\end{tabular}

\section{Tactical plan: control, respond, act, react}

\section{Figure 2 Mine planning strategic and tactical directions}

Strategic and tactical plans are summarised in lots of four. Initiatives are prioritised for having the highest payback in terms of safety improvement and economic benefit. Each initiative on its own should address technical opportunities that are sure to have safety merit and regularise the ore delivery to the smelter.

The first planned strategy, well underway now, is to standardise mine design software and best practice across the business, enabling strategic planning for larger areas. Its sister tactic has been prioritised on the shorter term design and forecasting capabilities. It targets the full utilisation of resources available in the short term to deliver long term objectives.

The second strategy is to proceed to the drafting of a Life of Resource Plan for each mining area. This is described in more detail in Section 3. The tactical plan aims at finalising and issuing final modifications to mining plans at least six months ahead of mining. This allows enough flexibility to embrace shorter term opportunities dictated by the environment and resource availability but also enables the alignment with the long term forecasted activities.

The third strategy is to quantify, using operational research calculations, the fleet requirements for the life of mine and manage the physical metrics into the financial plan. The tactical plan is to complete the full mine design six months ahead of the onset of operations and to integrate short term metrics into the overall fleet plan for tracking.

The fourth strategy is to focus on the materials handling system to manage the mass movement of material and address opportunities for improvement. Since an improvement plan has been made available to operations, its sister tactical activity is to implement the long term materials handling strategy including the addition of ore passes specially designed for a highly stressed environment and Perseverance's ore and waste handling requirements, for the life of mine.

Strategic and tactical directions are set and validated first; one can then proceed to the mine design avoiding a trial-and-error process. Section 3 summarises the process applied to mine design and implementation at Perseverance. 


\section{Mine design and layout}

The overall mine design and layout for Perseverance is rationalised and includes provisions for mine services and ventilation, emergency egress and refuge, and has adequate materials handling infrastructure that will sustain the production effort for the life of mine. Mine designs are provided ideally six months ahead of execution to ensure their quality. Perseverance mine engineering has reviewed its long term initiatives several times for investment review. The key learnings and recommended actions can be summarised as follows:

- Characterise the geological domains encompassing mining areas.

- Evaluate the in-situ ground stresses affecting the areas.

- Provide analysis of ground stresses throughout the life of mine openings including stoping areas, access ways and services, evaluate their impact on stability and formulate mining strategies accordingly.

- Consider optimising the position and orientation of mining access ways to align with the major principal stress whenever possible to minimise the exposure to ground stresses at mining abutments.

- Consider positioning main accesses and production access ways to be in the future shadow of planned stopes.

- Choose a tunnelling method and equipment type that is fit for purpose for Perseverance's mine environment.

- Provide analysis of static ground support requirements for the full service of mine openings.

- Provide sufficient seismic monitoring coverage for areas submitted to high stresses.

- Provide sufficient ground support for the foreseen velocity rating that could be imposed by dynamic loading on ground support systems.

The mine design process is summarised in Figure 3 (Szwedzicki, 2007). The onset of investment is triggered at the feasibility study stage. A set of conceptual designs are available and thoroughly reviewed to generate the Life of Resource Plan (LORP) for each mining zone, as separated by the investment strategy.

Once the LORP is reviewed by mine management and a production plan is agreed upon for the long term period, a set of preliminary mine designs is presented for review by mine operations. At this point, an optimised plan and schedule is available for the mining engineers in order to provide sustainable production rates from the cave, which delivers on a long term plan. The long term scheduling relies on feedback from the shorter term metrics. A very tight link is made with the mill metrics to deliver the mining product to the business as per the strategic Nickel West requirements.

Final designs are then reviewed and issued. Most of the engineering work stems from the Life of Resource Plan, thus at the conceptual design and scheduling stage and prior to the preliminary design stage.

The Life of Resources Plan (LORP) is a documented plan that is used to provide all of the necessary information required to safely and effectively implement the mining concept identified in a feasibility study. A LORP is required for each mining area within 12 months of the scheduled mining start date. The LORP develops functional and performance requirements that define the design requirements. The planning engineer must ensure that the requirements are understandable, unambiguous, comprehensive, complete and concise. The LORP is a "must do" plan for the mine operators. The plan is a prescriptive document that includes sufficient summary analysis and data in the text to justify the decisions reached.

The majority of the base information and concepts for the LORP will come from the feasibility study. The LORP preparation process will define the concepts further and provide more specific and detailed analysis for the mining area. The LORP will focus on translating the original concept into a set of requirements that can be used for operational planning and implementation. Table 1 lists the minimum requirements of the LORP document. 


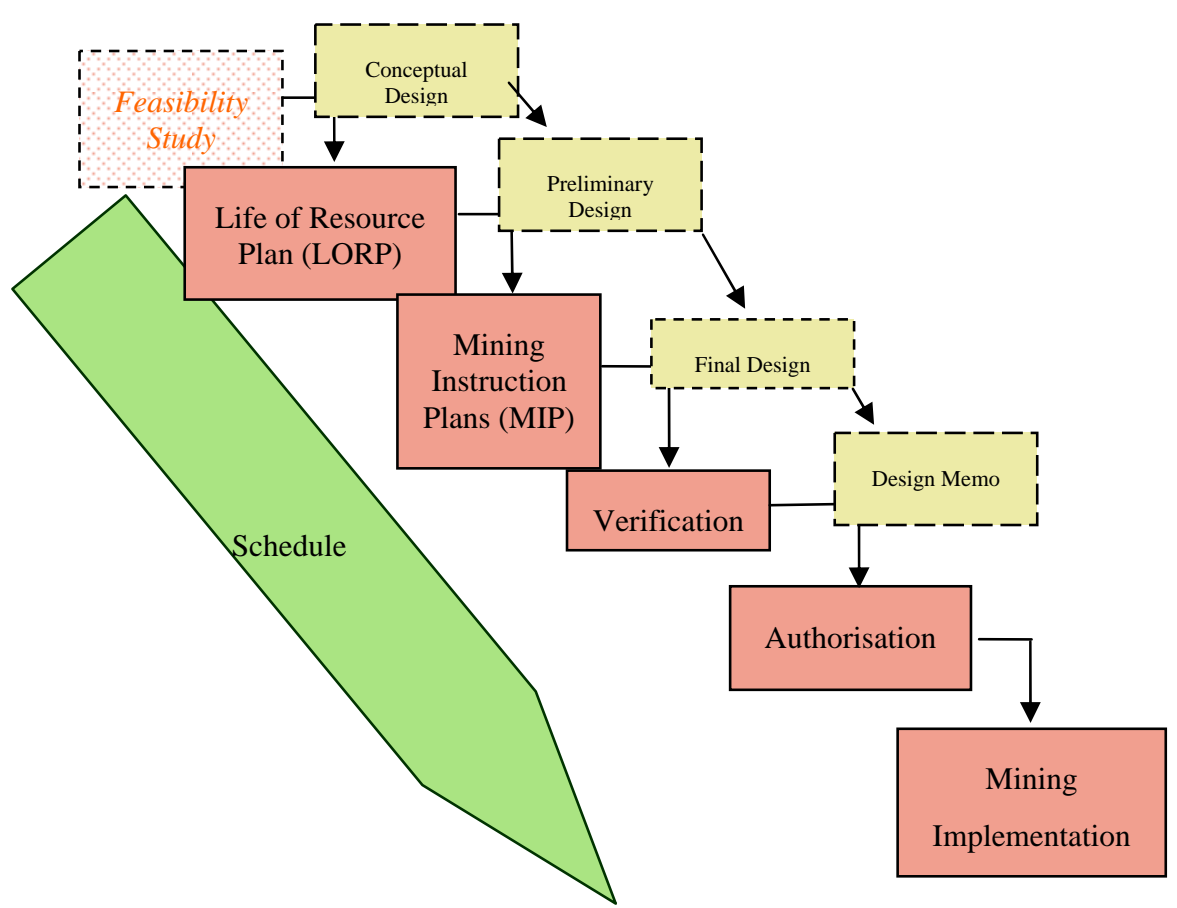

Figure 3 Mine planning process

Table 1 Minimum contents of the LORP

\begin{tabular}{ll}
\hline Topic & Content guideline \\
\hline Mining strategy & Alignment with strategic and Life of Mine requirements. \\
\hline Risk management & $\begin{array}{l}\text { The results of a risk assessment and the identified controls. The controls are to be } \\
\text { peer reviewed before finalisation in the LORP. }\end{array}$ \\
\hline $\begin{array}{l}\text { Geology and mineral } \\
\text { resources }\end{array}$ & Mineral resource, regional geology, structural geology, grade control. \\
\hline Mine planning & General mine planning criteria, access designs, mining method, production plan. \\
\hline $\begin{array}{l}\text { Geotechnical } \\
\text { considerations }\end{array}$ & $\begin{array}{l}\text { Regional stability, controls on interactions with adjacent ore bodies, likely } \\
\text { seismicity, ground stress, necessary ground support and monitoring requirements. }\end{array}$ \\
\hline Ore reserves & $\begin{array}{l}\text { Mineable resource, reserve factors, cut-off grade, categorisation, ore reserve } \\
\text { tabulation. }\end{array}$ \\
\hline Ore handling & Loading, hauling, ore-passes etc. \\
\hline Services & $\begin{array}{l}\text { Primary ventilation, secondary ventilation, escape ways, emergency controls, power, } \\
\text { air and water reticulation and compatibility with existing systems. Mine dewatering } \\
\text { etc. }\end{array}$ \\
\hline Equipment selection & Capacity and compatibility. \\
\hline Metallurgy & $\begin{array}{l}\text { A brief overview of metallurgical considerations particular to the relevant mining } \\
\text { area e.g. serpentinite / olivine ratios, iron/talc ratios or arsenic concentrations. }\end{array}$ \\
\hline Scheduling & \begin{tabular}{l} 
Development and production profile and matching this to the Life of Mine Schedule. \\
\hline Finance
\end{tabular} \\
$\begin{array}{l}\text { Projected capital and operating costs, revenues, cash flow etc using corporate } \\
\text { sanctioned methods and best practice. }\end{array}$ \\
\hline
\end{tabular}


The LORP is peer reviewed both internally and externally before sign-off and authorisation of the final version. The LORP is signed-off by the Underground Manager, Mine Planning Superintendent and other stakeholders as determined by the Underground Manager. Planned tonnage and development metres are scheduled and tracked and production gaps and excesses are carefully analysed and fed back to future planning considerations. Resource requirements are planned ahead and detailed scheduling is provided to reflect the resources availability. The key lesson here is that the more engineering is undertaken and consolidated ahead of mining, the better is the safety and productivity record for the activities.

The current status of all underground tunnelling and stoping plans are updated and displayed monthly in a set of Mine Instruction Plans (MIP) of A0 format available in the main concourse of the Perseverance Mine, near underground tagging boards. This visual aid facilitates a regular communication link to mine operations and an opportunity for feedback. The daily advance of tunnelling and stoping positions is hand written on plans by mine operations and the plans are a focal point of shift handover meetings.

The design memo (Figure 4) is the mechanism by which authorisation is granted to the final design. It is also a communication to survey to issue a development work-plan or for the Drill and Blast Department to issue ring design or to assign a drill rig to drill a service hole. The design memo should carry sufficient information to convey the context and requirements of the design and identify risks and control measures that are pertinent to implementation. The design memo is issued for approval in A0 or A3 paper size, the former for a full sub-level design approval, the latter for the detailed design and modifications of portions of a level. By delivering the design memo to the Survey Department, the mine planning process has had to go through numerous review processes that ensure that the design is of sufficient quality and fit-for-purpose for the deep mining environment of the Perseverance Mine and incorporates key information from the collective experience.

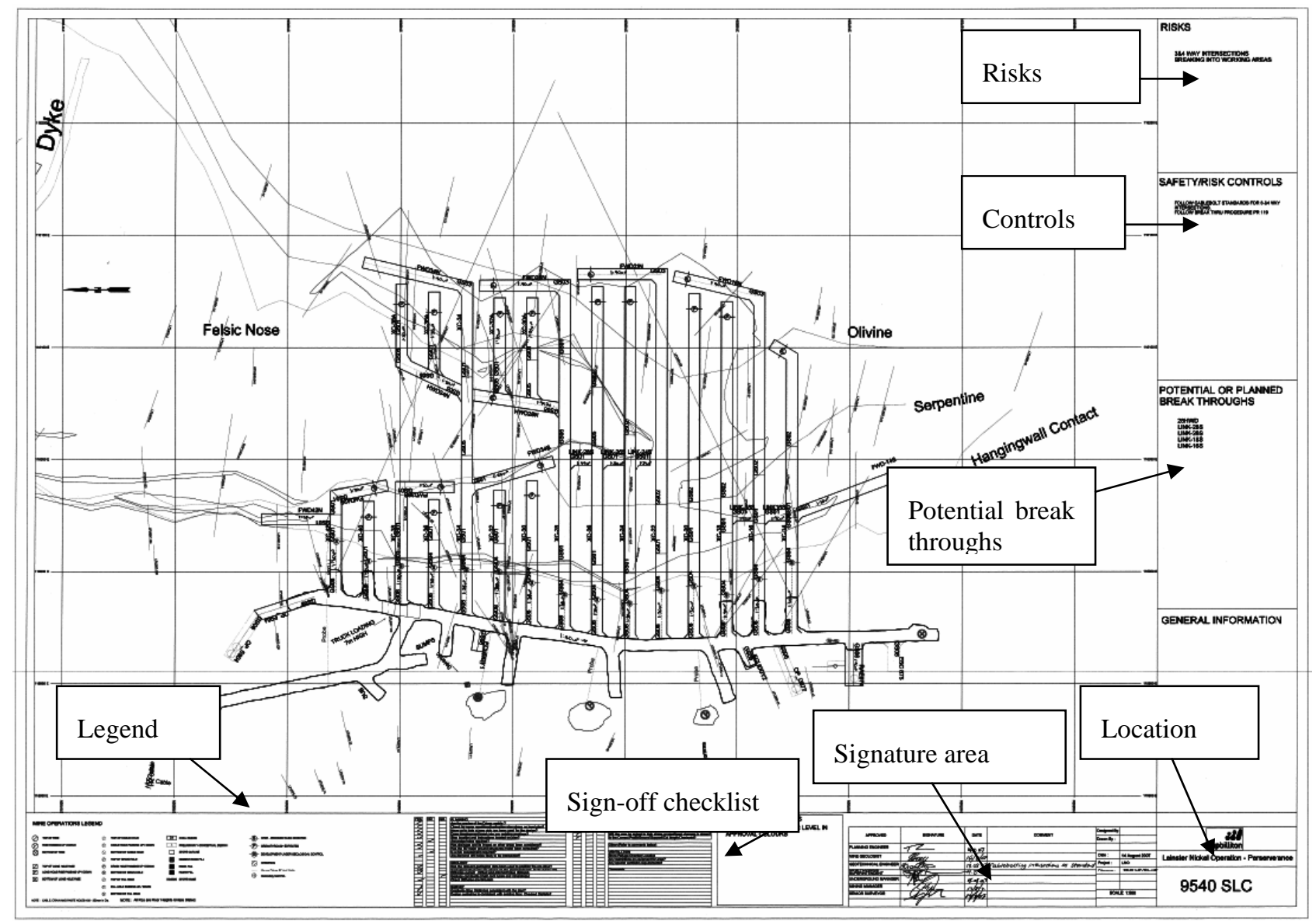

Figure 4 Design memo (annotated; A0 paper size) 


\section{Ground support and geotechnical improvements}

An important aspect of mine planning for deep mining is to "yield" to high ground stresses, that is, to avoid choosing mining strategies that rely on techniques and methods that are most likely to be adversely affected by the high stress environment. For instance, the placement of materials handling infrastructure into high stress areas is likely to impact on its reliability. Another example would be to design for access ways that are heavily reinforced using ground support to cater for high stress conditions as opposed to placing the access way in a more favourable orientation that still fulfils its function. One proceeds to the design of tunnel reinforcement based on best practice once all possible considerations have been given to plan the mine relying on design considerations that minimise the adverse effect of the high stress environment, such as those listed previously.

Perseverance mine still uses a relatively large amount of ground support as compared to benchmark SLC mines. This is due to the nature of ground stresses on site but also because of the relatively poor quality of the felsic to ultramafic contact that must be traversed in every cross-cut hosting the nickel. The contact area behaves unfavourably when subjected to ground stresses and produces squeezing ground conditions. For this reason a three-pass ground support regime is used for the production cross-cuts; a layer of shotcrete (sprayed concrete), followed by the installation of mesh and bolts and then the application of a second layer of shotcrete.

The quantity and quality of ground support must withstand conditions ranging from squeezing ground to dynamic loading from mining-induced seismicity. Tendon support types used to stabilise the ground are assessed for their reliability in these conditions and minor adjustments are provided to the support schemes for safe access and to sustain the production. Over its operating history, several ground support systems have been trialled and implemented at Perseverance Mine with excellent results for controlling squeezing and dynamic loading conditions, as well as minimising the amount of tunnel rehabilitation required on an annual basis. The scope remains to improve on these practices and design for continuous improvement on these systems. Refer to Thin et al., 2006 as well as Gaudreau, 2006a and 2006b for more information on geotechnical considerations for deep mining at Perseverance mine.

Resources are also invested in the sustainable improvement of the materials handling system, including ore passes, tipping accesses and hoisting arrangements. Ore passes can suffer from high stress conditions, seismic damage, abrasion and impact wear. Since the current ore pass network cannot be shadowed by the mining of openings, the current control to decelerate the wear is based on choke feeding. The ore passes are operated to ensure that they contain a certain quantity of material at all times, in order to confine the ore pass walls and prevent delamination due to impact and stress.

Perseverance Mine uses mass mining methods that result in lateral deformation and subsidence in the rock mass. The subsidence profile generated by the cave is monitored on surface and underground. It is expected that the main production shaft will eventually be affected by subsidence from the cave. This could potentially generate distortions to the shaft guides and affect the reliability of its operation. A preventative measure is to regularly inspect and measure the influence of the rock mass movement on the shaft's integrity. This is accomplished through tilt meters, visual inspections, time domain reflectometry (TDR) and shaft centreline tilt surveys. Aerial photogrammetry, prism and GPS monitoring are also used as an aid to the interpretation of surface subsidence that results from cave mining.

\section{Conclusion}

There is scope within the Leinster Nickel Operations to pursue deep mining and to apply mass mining techniques. An intense level of effort has been invested in studying mass mining techniques by the international caving studies, and LNO has been at the forefront of case studies with its sub-level cave at Perseverance Mine. After more than ten years in operation, a few lessons have been learned that helped prepare for the future at Perseverance Deeps. This starts with the careful planning of mining strategies that add value to the business. This is achieved through the formulation of business plans for the division, but also in the formulation of strategies and tactics for mine operating departments as well as projects under feasibility study. 
For a deep level mine, once mining strategies have been identified and reviewed, significant benefit is gained by completing as much engineering as practicable on the mining plan. The ultimate example of this is that of the design of a block caving mine, whereby all the mining and infrastructure requirements are normally designed to a significant level of confidence well ahead of the start of the project. Sub-level cave mining at deep levels also requires this level of front loading of engineering and the application of such methods has significant benefits on safety and production metrics.

\section{Acknowledgements}

The authors would like to gratefully acknowledge Karl van Olden, Alan Cooper, Peter Lock, Tony Carr, Lisa O'Connor and Chris Stone for their participation in this work as well as acknowledge BHP-Billiton Nickel West for permission to publish this paper.

\section{References}

Carthew, G., Auld, B. (2006) PDP OWC Report Mining. BHP-Billiton internal report.

Gaudreau, D. (2006a) Geotechnical Engineering Management Considerations for Mining Operations at Depth. Deep and High Stress Mining, Quebec City.

Gaudreau, D. (2006b) Current Ground Support Practices at Perseverance Mine. Deep and High Stress Mining, Quebec City.

Szwedzicki, T. (2007) Procedure on Mine Planning. BHP-Billiton internal procedure.

Thin, I., Stone, C., Beck, D. and Hastings, N. (2006) Perseverance Mine: Past, Present and Deeper - Part III. ${ }^{\text {nd }}$ International Seminar on Strategic vs Tactical Approaches in Mining, Perth, Australia. 8-10 March 2006, Section 7, pp.1-15. 